\title{
O caráter de prova dos documentos produzidos pelas DOPS
}

\author{
Caroline Almeida Sodré
}

\author{
Mestre em Ciência da Informação (UnB) \\ e Bacharel em Arquivologia (UnB)
}

Cynthia Roncaglio

Docente do Curso de Arquivologia e do
Programa de Pós-Graduação em Ciência
da Informação (PPGCInf) da Faculdade
de Ciência da Informação (FCI) da
Universidade de Brasília (UnB)

http://dx.doi.org/10.1590/1981-5344/2623

Este artigo tem como objetivo, a partir da revisão de literatura e da análise documental, avaliar se a documentação produzida pelas Delegacias de Ordem Política e Social (DOPS), no contexto do aparato repressivo do Regime Militar Brasileiro (1964-1985), possui características de prova documental. Partindo-se da análise diplomática e dos sentidos atribuídos ao conceito de prova documental, identifica-se que algumas tipologias documentais da DOPS possuem caráter de prova no sentido de serem 'legitimadoras de discursos'. Também podemos citar a importância desses acervos no processo de redemocratização no Brasil que culminou na promulgação da Lei de Acesso à Informação no 12.527, de 18 de outubro de 2011, e ainda os trabalhos da Comissão Nacional da Verdade, que utilizou maciçamente a documentação das DOPS para investigação da violação de direitos.

Palavras-Chave: Delegacias de Ordem Política e Social; DOPS; Prova Documental; Regime Militar Brasileiro. 


\section{The character of documentary evidence of the documents produced by the DOPS}

The objective of this paper is to analyze the documentation produced by the Police Departments of Political and Social Order (DOPS), in the context of the repressive apparatus of the regime Brazilian Military (1964-1985), it has documentary evidence. Starting from the literature review, the diplomatic and analysis of the meanings attributed to the concept of documentary evidence identifies that some types of DOPS have character of documentary evidence of in the sense of being 'legitimating of discourses'. And can also mention the importance of these archives in the democratization process in Brazil which culminated in the enactment of the Access to Information Law no. 12,527, of October 18, 2011, and also the work of the National Truth Commission, which massively used the documentation of this Police Departments of Political for investigation violation of rights.

Keywords: Police Station Political and Social Order; DOPS; Documentary Evidence; Brazilian Military Regime.

Recebido em 16.11.2015 Aceito em 12.07.2017

\section{Introdução}

O presente trabalho apresenta uma revisão da literatura e análise documental, buscando compreender se a documentação produzida pelas Delegacias de Ordem Política e Social (Dops), no contexto do aparato repressivo do Regime Militar Brasileiro (1964-1985), possui caraterísticas de prova documental, tendo como base o trabalho de Rabello e Rodrigues (2014).

A prova documental pode ser analisada sob vários aspectos, sobretudo se levarmos em conta as atividades das DOPS como uma polícia política inserida em um regime de exceção. Várias são as problemáticas referentes aos usos dessa documentação: em primeiro lugar, pode-se atentar para a sua utilização primária, no âmbito das funções e atividades da instituição que o produziu. Em segundo lugar, com a mobilização social pela redemocratização do Brasil e a extinção das Delegacias, esses documentos não se tornaram apenas provas de atividades e procedimentos administrativos de uma DOPS extinta, mas 
passaram também a ser utilizados como prova material de graves violações aos direitos humanos, vindo inclusive a compor processos de reparação às vitimas do regime e seus familiares e responsabilização do Estado pelas atividades desenvolvidas pelos agentes dentro do seu aparato repressivo.

Importante salientar que essa Polícia Política era descentralizada. As DOPS eram órgãos estaduais, vinculadas geralmente as Secretaria de Segurança Pública (à exceção da DOPS-DF, que era vinculada à Polícia Federal). Mesmo possuindo funções semelhantes sua denominação variava de estado para estado, sendo algumas chamadas de Delegacias e outras de Departamentos. Como essa divergência de nomenclatura não é salutar para o presente trabalho, optamos por utilizar o nome Delegacias de Ordem Política e Social para nos referirmos a todos esses órgãos estaduais de polícia política, com base nos postulados de Ishaq, Franco e Sousa (2012) ${ }^{1}$.

\section{0 papel das DOPS dentro do aparato repressivo do Regime Militar (1964-1985)}

As Delegacias de Ordem Política e Social (DOPS) foram criadas nos Estados durante a década de 1920, vinculadas às Secretarias de Segurança Pública. Este era um momento histórico de grandes movimentações políticas em nível nacional e internacional, haja vista o descontentamento de grande parte da população com o regime vigente.

Nessa época o Brasil vivia no período conhecido como República Velha (1894-1930), onde os governantes provinham das famílias oligárquicas dos estados de Minas Gerais e São Paulo, que se revezavam no poder. Esse sistema beneficiava as elites agrárias, produtoras de café (São Paulo) e de leite (Minas Gerais), que eram favorecidas pelo governo em troca de apoio político.

Tendo em vista essa conjuntura, surgiram movimentos contrários à política café-com-leite ${ }^{2}$, provindos principalmente dos centros urbanos (que eram menos influenciados pelo coronelismo). Araújo cita em seu trabalho esse momento de descontentamento e rebelião, que dá ensejo à criação das DOPS:

Nesse momento, percebe-se, da parte das classes dirigentes, a tentativa de se implementar um amplo aparato de cunho administrativo-legal a fim de controlar todas essas manifestações de descontentamento político. Do ponto de vista administrativo, órgãos específicos surgiram, dentro da máquina do estado, com a função específica de controle político-social (dos quais, o DEOPS/SP é um bom exemplo) (ARAÚjO et al., 2001, p. 23).

\footnotetext{
${ }^{1}$ As Delegacias de Ordem Política e Social: "órgãos policiais de repressão política criados na década de 1920 e que estiveram a serviço da ditadura militar, sendo extintos em 1983 [e tendo como] função primordial o controle e a repressão de movimentos políticos e sociais contrários ao regime militar" (ISHAQ; FRANCO; SOUSA, 2012, p. 126).

2 Segundo Fagundes, são reflexos do descontentamento de setores da população com o regime vigente "o movimento Tenentista, a Reação Republicana, a Semana de Arte Moderna, a 'Revolução de 1924', a Coluna Prestes e a fundação do Partido Comunista do Brasil" (FAGUNDES, 2010, p. 128).
} 
Para Aquino as DOPS eram "um dos mais importantes órgãos do aparato repressivo da História Republicana Brasileira" (AQUINO, 2001, p. 16). Sua função era de uma polícia política que, no transcurso de suas atividades, se utilizou de práticas que ferem os direitos humanos (como tortura e outras práticas de cunho violento) com vistas à obtenção de informações e a repressão dos grupos tidos como "subversivos", conforme explicita Araújo et al. (2001, p. 24):

Estando sempre [devotadas] à vigilância, controle e repressão dos setores e cidadãos engajados em projetos políticos alternativos aos implementados pelos donos do poder. Nesse exercício de dominação, lançou mão de práticas violentas e ilegais (como tortura, o cárcere privado e a execução sumária), métodos amparados na legislação (como a instauração de inquéritos policiais) e também da produção e armazenamento de uma quantidade enorme de informações sobre cidadãos considerados "perigosos" para a ordem vigente.

As DOPS eram conhecidas pela sua caraterística de polícia política. Para Xavier, a polícia política seria um tipo de "especialização" da polícia comum, tendo como enfoque os ditos crimes políticos e sociais. Essa modalidade de polícia seria, no contexto brasileiro, responsável por inibir reações políticas adversas, tendo uma função preventiva e repressiva no contexto do Brasil (XAVIER, 1996, p. 32). Seria o dever da polícia política:

Estar à disposição dos governos quando esses decidissem vigiar e/ou aprisionar certos indivíduos, combater determinados comportamentos e estigmatizar grupos inteiros (imigrantes, dissidentes políticos, pobres das cidades) tidos sempre como 'nocivos' e perigosos para a ordem pública e a segurança nacional (SOMBRA, 1996, p. 41).

Vale lembrar que, para Araújo et al. (2001), a vigilância não era ampla e irrestrita, mas seguia uma lógica em que algumas esferas sociais seriam "mais perigosas" que outras. Podemos citar, como exemplo, os membros de organizações sindicais e jornalistas. Ou seja, alguns grupos "tendiam mais ao crime" do que outros. Isso gerava uma vigilância desigual, já que alguns eram mais vigiados (e reprimidos) do que outros. Fato reafirmado por Negro e Fontes quando dizem que "as entidades consideradas mais "perigosas" recebiam monitoramento mais detalhado. Assim, o cotidiano de várias delas foi sistematicamente observado e registrado - em alguns casos, ininterruptamente ao longo de décadas" (NEGRO; FONTES, 2001, p. 163).

A ação das DOPS começa a se destacar primeiramente durante o Estado Novo (1937-1945), onde suas atividades assumiram papel importante no "processo de domesticação das massas", já que o governo vigente "buscava, como a maioria dos regimes autoritários, o singular, ou seja, a homogeneidade em todos os níveis, de forma a facilitar a 
dominação, o controle" e "um de seus principais objetivos - parte integrante do projeto político do Estado - era bloquear a heterogeneidade de pensamento procurando silenciar aqueles que eram considerados 'potencialmente perigosos'"' (CARNEIRO, 1999, p. 335-336).

Com a instauração de um novo regime político no Brasil, a partir de 10 de abril de 1964, os órgãos de cunho repressivo que existiam anteriormente (como as DOPS) se congregaram a outros criados após o golpe, ganhando novos papeis no novo contexto, conforme afirma Bauer (2006):

A montagem desse aparato repressivo foi feita através da criação de novos órgãos que congregaram-se aos existentes antes do golpe, como os Departamentos de Ordem Política e Social (DOPS), que foram criados subordinados às Secretarias de Segurança Pública (SSP) dos Estados brasileiros durante as décadas de 1920 e 1930 (BAUER, 2006, p. 16).

No mesmo ano do golpe, mais precisamente em 13 de junho de 1964, por meio da Lei no 4.341 (BRASIL. Presidência da República, 1964), foi criado o Sistema Nacional de Informações (SNI). Este tinha como finalidade "superintender e coordenar, em todo o território nacional, as atividades de informação e contra informação, em particular as que interessem à Segurança Nacional"'3 (BRASIL. Presidência da República, 1964).

Idealizado pelo General Goldbery do Couto e Silva, o SNI "combinava as funções de uma agência central de informações com as de um órgão assessor para formulação de políticas nacionais" (DREIFUSS; DULCI, 2008, p. 167). Ele centralizou uma rede de informações, interligando vários órgãos do poder público e colhendo dados dentro dos mesmos e em várias esferas da sociedade brasileira (sob o argumento da preservação da segurança nacional). O SNI antecipou algumas funções do futuro Serviço Federal de Informação e Contra Informação (SFICI) (DREIFUSS; DULCI, 2008, p. 168).

Importante salientar que o General Golbery (idealizador do SNI), acreditava que ante a ameaça à segurança nacional era justificável o sacrifício ao bem estar social, ou seja, impor a "limitação da liberdade, das garantias constitucionais, dos direitos da pessoa humana" (COIMBRA, 2000, p. 10).

Segundo Pereira e Reznik (1996), com o golpe de 64 se instaurou no Brasil o Estado de Segurança Nacional, cujos órgãos centrais iriam orientar as atividades das polícias políticas estaduais. Esses órgãos de inteligência formariam um intercâmbio informacional (cujo "cabeça" seria o Serviço Nacional de Informações), constituindo assim a Comunidade de Informações:

A Comunidade de Informações, preconizada pela Doutrina de Segurança Nacional, estabelece como seus órgãos centrais o recémcriado Serviço Nacional de Informações (SNI) e os órgãos de

\footnotetext{
${ }^{3}$ Art. $2^{\circ}$ da Lei no 4.341, de 13 de junho de 1964 (BRASIL. Presidência da República, 1964).
} 
inteligência militares (CIEX, CISA e CERIMAR ${ }^{4}$ ). Elaborando estratégias, produzindo informações e centralizando os informes são, indubitavelmente, os agentes mais categorizados da repressão. (PEREIRA; REZNIK, 1996, p. 43).

Nesse novo contexto, "o processamento e elaboração de estratégias e 'informações' estão confiados aos órgãos centrais (SNI e militares); cabe [às] DOPS municiá-los de 'informes'" (PEREIRA e REZNIK, 1996, p. 43). 0 novo contexto brasileiro fez com que os órgãos repressivos anteriores ao regime (como as DOPS), que detinham certa autonomia entre si, se tornassem uma estrutura única, conforme Magalhães (1997):

À diferença dos aparatos repressivos preexistentes, em que as unidades de força militares ou policiais guardavam autonomia de ação entre si, este pretendeu consolidar uma estrutura única e coesa, como uma rede inextricável, cujas ações eram coordenadas a partir de um núcleo central, o Serviço Nacional de Informações SNI. (MAGALHAES, 1997, p. 2).

Dentro do contexto repressivo que se instaurou no Brasil após 1964, as DOPS mantiveram suas atividades de polícia política, mas com a diferença de estarem agora subordinadas ao SNI e fazerem parte da "comunidade de informações" (rede de informação e contrainformação dentro do regime militar).

Importante salientar que elas eram a "base da pirâmide" encabeçada pelo SNI. A elas cabia a construção e a formalização dos documentos e elementos investigativos que viriam a compor os Inquéritos Policiais Militares (IPMs).

Bauer (2006) em sua dissertação sobre a ação da DOPS no Rio Grande do Sul aponta a importância dessa delegacia na produção das informações que viriam a compor os IPMs, atribuição essa com a característica de uma polícia judiciária (BAUER, 2006, p. 18). O Relatório I da Comissão Nacional da Verdade (em seu tópico dedicado à DOPS de Minas Gerais) ratifica essa função crucial das delegacias:

A principal função do DOPS de Minas Gerais foi a condução dos inquéritos policiais militares (IPM), implantados a partir de 1964 [...]. Com o recrudescimento do regime, os IPM se tornaram mecanismos legais gerais para a busca sistemática de informações de segurança. O órgão possuía duas frentes de trabalho para a realização de todos os procedimentos investigativos atinentes ao IPM: interrogatórios, busca e apreensão, perícias e vistorias. [...] Embora instituídos no âmbito burocrático do DOPS, IPM foram presididos por oficiais militares da 4a Região Militar. Na execução dos IPM, o DOPS teve apoio e cooperação de informações do Serviço Nacional de Informações (SNI), área Belo Horizonte $(A B H)$, e nas

\footnotetext{
${ }^{4}$ CIEX - Centro de Informações do Exército; CISA - Centro de Informações da Aeronáutica; CERIMAR - Centro de Informações da Marinha.
} 
operações de busca e apreensões da Polícia Militar de Minas Gerais. (BRASIL. Comissão Nacional da Verdade, 2014, p. 774).

Nos idos dos anos 1969 com a criação dos Destacamentos de Operações Internas - Centro de Operações de Defesa Interna (DOICODIs) (oriundos da Operação Bandeirantes - OBAN), as DOPS passaram também a conferir legalidade aos documentos produzidos dentro dos DOI, que também produziam informações relevantes para a composição dos IPM:

Dos IPM 'A formação dos inquéritos policiais de presos políticos era, a partir de 1969, dividida em duas partes: a fase dos DOI-CODIs ou dos organismos de segurança das Forças Armadas; e a do 'cartório', em que os presos passavam à disposição dos DOPS ou da Polícia Federal, encarregados de 'formalizar' os inquéritos. [...] Nas investigações realizadas nos DOI-CODIs, não havia encarregado de inquérito, com as atribuições estabelecidas pela CPPM ${ }^{5}$. Em geral, os delegados do DOPS ou da Policia Federal figuravam formalmente como encarregados desses inquéritos, os quais procuravam 'legalizar' aquilo que os DOI-CODIs haviam produzido'. (ARQUIDIOCESE DE SÃO PAULO, 1986, p. 173174).

Tais fatores explicam a grande quantidade de documentos produzidos no âmbito das DOPS posto que, além daquela documentação, fruto de suas atividades investigativas, tinham também documentos com as informações produzidas nos interrogatórios dos DOI.

Essas delegacias não tinham a função apenas investigativa, atuando na constituição dos inquéritos policiais, mas também tinham um viés repressivo, sendo elas grandes responsáveis pela prisão e tortura de presos, conforme salientam Araújo et al. (2001):

Além da tarefa preventiva, tinha[m] a função de investigar crimes eventualmente cometidos, instaurando inquéritos policiais para serem remetidos ao Poder Judiciário. Dessa maneira, [os órgãos] exercia[m] simultaneamente atividades ligadas à prevenção (atuando antes do crime) e à repressão (colaborando com o Judiciário para a punição do crime). Obviamente, que tanto na prevenção quanto na repressão de crimes, [as DOPS destacaramse] pelo emprego de métodos ilegais e mesmo violentos. (ARAÚjo et al., 2001, p. 35).

Assim, a atuação dessas delegacias dentro do complexo sistema de informações formado pelos órgãos da "comunidade de informações", sob o argumento de promover a segurança nacional protegendo o país do "inimigo interno", não respeitava nenhum postulado que preservasse o cidadão da ação repressiva do Estado. Sob a égide da "lógica da desconfiança", pessoas eram torturadas dentro de instituições públicas para que fornecessem as informações que os agentes públicos buscavam,

\footnotetext{
${ }^{5}$ Código de Processo Penal Militar.
} 
conforme depoimento de uma ex-militante constante do Relatório I da CNV:

As torturas e maus tratos sofridos foram praticados nas instalações do DOPS - Departamento de Ordem Política e Social, órgão da Secretaria de Segurança Pública do estado, por agentes da Polícia Civil ali lotados, bem como por militares do Exército brasileiro (BRASIL. Comissão Nacional da Verdade, 2014, p. 761).

Com o enfraquecimento do regime e a redemocratização do país, as DOPS começaram a ser extintas nos idos dos anos 1980. Existia (e ainda existe) um clamor da sociedade para que essa documentação se tornasse/torne-se disponível. Isso deu ensejo ao recolhimento desses acervos a arquivos e universidades públicas.

\section{Algumas tipologias documentais}

Segundo Bellotto "a tipologia documental é a ampliação da diplomática em direção da gênese documental, perseguindo a contextualização nas atribuições, competências, funções e atividades da entidade geradora/acumuladora" (BELLOTTO, 2008, p. 7). Ou seja, a tipologia documental extrapola os objetivos da diplomática, buscando não só entender seus caracteres internos e externos, mas também o documento como componente de conjuntos orgânicos.

Podemos entender a tipologia documental como sendo a espécie ${ }^{6}$ documental acrescida da função do documento, "sua denominação será sempre correspondente à espécie anexada à atividade concernente e vale como conjunto documental representativo da atividade que caracteriza" (BELLOTTO, 2008, p. 72).

No caso das tipologias produzidas no decurso das atividades das DOPS, são mais conhecidos os Atestados de Antecedentes Políticos e Sociais e as Fichas Individuais.

O Atestado de Antecedentes Políticos e Sociais, também conhecido como Atestado Ideológico ou Atestado de Ideologia Política, era um documento expedido pelas DOPS e fornecido àqueles que não eram fichados pelo órgão, ou seja, não eram considerados 'subversivos'. Este documento era exigido por muitas empresas durante o regime militar como requisito para a contratação de funcionários e era obrigatório para a escolha de dirigentes sindicais.

Tal documento pertence à espécie 'atestado' que, retomando os subsídios teóricos de Bellotto, é considerado um:

Documento diplomático testemunhal de assentamento, horizontal. Declaração, por autoridade governamental, civil, militar, eclesiástica ou notarial, a partir de uma realidade ou de um fato constatado. É,

\footnotetext{
6 "A espécie documental é a configuração que assume um documento de acordo com a disposição e a natureza das informações nele contidas" (CAMARGO, A. M; BELLOTTO, H. L. Dicionário de terminologia arquivística. São Paulo: Secretaria de Estado da Cultura do Estado de São Paulo, 1996 apud BELLOTTO, 2008, p. 31).
} 
em geral, a favor de uma pessoa e confeccionado a seu pedido (BELLOTTO, 2008, p. 36).

A diplomática, como ciência documentária, nasce no século XVII e "ocupa-se com a estrutura formal dos atos escritos de origem governamental e/ou notarial" (BELLOTTO, 2006, p. 45). Os documentos diplomáticos são os instrumentos pelos quais se materializam os atos jurídicos/administrativos, ou seja, eles podem modificar, comprovar, resguardar ou extinguir direitos. "São aqueles de natureza estritamente jurídica que refletem, no ato escrito, as relações políticas, legais, sociais e administrativas entre o Estado e os cidadãos" (BELLOTTO, 2006, p. 51).

Dessa forma o Atestado de Antecedentes Políticos e Sociais era um documento diplomático emitido pelas DOPS com a finalidade de comprovar que o requerente não tinha ficha aberta em seu nome na polícia política, ou seja, essa tipologia cumpria a função de declarar que o cidadão possuía 'bons antecedentes políticos e sociais'. Seria ele um documento testemunhal de assentamento por derivar de registros oficialmente escritos sobre fatos ou ocorrências (no caso do atestado de antecedentes políticos, da falta desses fatos/ocorrências), atestando que o requerente tinha a 'ficha limpa'.

A diferença entre os documentos ascendentes, descendentes e horizontais (que é o caso do Atestado de Antecedentes Políticos e Sociais) se situa no modo com que essa documentação é transmitida entre autoridades e pessoas. Bellotto (2002) explica essa diferença usando como exemplo a circulação de papéis dentro de uma monarquia:

A circulação dos papéis é feita em direções opostas, segundo se trate, por um lado, dos que descem do Rei e das autoridades superiores - os documentos descendentes -, por outro, dos que sobem dos súditos às instâncias superiores - os documentos ascendentes (CORTÉS ALONSO, 19867). Há ainda os documentos horizontais, isto é, os que se distribuem entre autoridades/pessoas ou autoridades do mesmo nível (BELLOTTO, 2002, p. 37, grifo nosso).

Ao contrário de obter um Atestado de Antecedentes Políticos e Sociais, ser 'fichado' pelas DOPS, ou seja, constar uma ficha individual nos arquivos das Delegacias em seu nome, significava enfrentar determinados constrangimentos no período ditatorial brasileiro, conforme afirma Benedito (2012):

Ser fichado pelo Dops, em certos momentos, representava grandes problemas. No mínimo, dificuldade para arrumar emprego, pois numa fase da ditadura iniciada em 1964 muitas instituições e empresas exigiam do candidato a seus empregos uma coisa chamada "Atestado de Antecedentes Políticos e Sociais", mais conhecido como "Atestado Ideológico", fornecido pelo Dops aos que

7 CORTÉS ALONSO, V. La forma de los documentos: la tradición documental. In: LA ESCRITURA y lo escrito: paleografia y diplomatica de los siglos XVI, XVII y XVIII. Madrid: Ministerio de Cultura, 1986. 
não tinham ficha em seus arquivos. Para fichados suspeitos de envolvimento com organizações de esquerda, era pior. Podiam ser e eram - presos sob qualquer pretexto e acusados de qualquer coisa (BENEDITO, 2012) ${ }^{8}$.

Retomando as questões tipológicas, a Ficha Individual (ou registro técnico) pertence à espécie 'ficha'. Ainda de acordo com os postulados de Bellotto esta seria um "documento não-diplomático, informativo. Formato padronizado que ganha categoria de espécie documental quando abriga informações sucintas para fins específicos, que se evidenciam no próprio título da ficha" (BELLOTTO, 2008, p. 53).

A Ficha Individual não é um documento diplomático já que, apesar de haver a possibilidade de ser enquadrado nos parâmetros de veracidade postulados pela diplomática, a sua produção não deriva do fato jurídico/administrativo e também não visa à comprovação, extinção e modificação de direitos. Ela seria, conforme Bellotto, um documento lato sensu já que "a natureza jurídico-administrativa [do conteúdo de um documento diplomático] exclui outro documento que não tenha sido gerado com a expressa finalidade de consignar um ato que comporte efeitos jurídicos concretos" (BELLOTTO, 2006, p. 47).

Além dos Atestados de Antecedentes Políticos e Sociais e das Fichas Individuais, as DOPS produziam muitas outras tipologias documentais. Algumas se tornaram muito conhecidas, como os Dossiês Pessoais e Temáticos ${ }^{9}$, e outras nem tanto, como as Guias de Identificação de Presos $^{10}$.

\section{Os documentos das DOPS e seu caráter de prova documental}

Conforme Rabello e Rodrigues (2014) é possível compreender três sentidos para o conceito de prova documental: 1) "aprisionamento da palavra", que subentende a autenticidade e a fidedignidade dos documentos oficiais, que necessitariam por sua vez de locais específicos para promover sua guarda e acesso; 2) "representação da realidade", ideia muito utilizada no período de cientificismo e pelo movimento historicista, onde o conteúdo dos documentos era "enaltecido" e se buscava, tanto quanto possível, extinguir pontos de vista pessoais na interpretação das informações; 3) "legitimação dos discursos", ligado ao movimento dos Annales (ou história nova), que se utiliza da premissa que o entendimento da realidade pode estar muito além da informação registrada nos documentos. O documento não é mais a representação

\footnotetext{
8 Disponível em: <http://www.revistaforum.com.br/blog/2012/02/ate-marx-era-fichado-no-dops/>. Acesso em: 6 jul. 2015.

${ }^{9}$ Pertencentes à espécie 'dossiê', "documento não-diplomático, informativo, horizontal. Unidade documental na qual se reúnem informalmente documentos de natureza diversa com uma finalidade específica" (BELLOTTO, 2008, p. 51).

10 "Documento diplomático testemunhal, de assentamento, descendente" (BELLOTTO, 2008, p. 54).
} 
inequívoca da realidade, mas sim um elemento de legitimação de discursos. Assim, para os autores,

Os dois primeiros conceitos [sic] identificados são complementares. O primeiro privilegia o 'aprisionamento' do registro num suporte e o lugar de guarda deste como critério de legitimidade. O segundo assume, mediante tal 'aprisionamento', a prerrogativa da 'representação' inequívoca da realidade.

O terceiro conceito [...] [entende que] todo documento é um discurso constituído ou constituinte. Assume, na vida social dos objetos, o caráter evidencial da informação registrada para além da escritura. (RABELLO; RODRIGUES, 2014, p. 180).

Esse local específico para a guarda dos documentos, na visão de prova documental como "aprisionamento da palavra", é comumente o arquivo. Nessa acepção, um documento sob custódia de uma instituição arquivística já é, só por esse fato, uma prova documental e essa "dimensão de prova dos documentos oficiais escritos armazenados nos arquivos passa a ser corroborada pela diplomática" (RABELLO e RODRIGUES, 2014, p. 167).

Os historicistas, como já dito, entendiam a prova documental como "representação da realidade". Para eles seriam "somente os documentos escritos - contidos nos arquivos - [...] fontes históricas válidas" (RABELLO; RODRIGUES, 2014, p. 169). Essa corrente de história tradicional se baseava apenas na documentação oficial.

Por fim temos a prova documental como "legitimação dos discursos". Tendo sua base no movimento dos Annales, essa nova história não negava a que vinha sendo feita pelos historicistas, mas questionava o sentido estrito que a documentação tinha para esses historiadores. A história nova, reconhecendo a intencionalidade presente na produção documental, se preocupa também com a análise das estruturas sociais e das circunstâncias nas quais esses documentos foram produzidos.

Baseadas nos autores anteriormente citados e na análise documental, consideramos que os documentos da DOPS possuem um caráter de prova, contemplando esses três aspectos mencionados. Porém as questões relativas a essa documentação como "aprisionamento da palavra" e como "representação da realidade" são discutíveis, tendo em vista que, no caso das DOPS, tratavam-se de delegacias inseridas em um contexto repressivo, onde a representação do fato ocorrido não pode ser entendida apenas com base na documentação de arquivo, mas também no contexto em que essa informação foi produzida é imprescindível para a compreensão (e reconstrução) do que realmente aconteceu. Nesse sentido, o conceito de prova documental como "legitimação de discursos" se torna mais apropriado para a documentação produzida no decorrer das atividades dessas polícias políticas.

Corrobora esse pensamento não estrito e relativista, que deve nortear os estudos baseados nesse tipo de acervo, o trabalho de Rodrigues (2014), que busca problematizar os conceitos de verdade e 
autoridade de arquivo tendo como plano de fundo o óbito do jornalista Vladimir Herzog ${ }^{11}$.

No atestado de óbito de Herzog constava como causa da morte "asfixia mecânica por enforcamento" e compunha o Inquérito Policial Militar (IPM) (aberto para apurar sua morte, tendo em vista as alegações de que o jornalista não havia se suicidado) uma fotografia tirada nas dependências do DOI-CODI que "comprovaria" o suicídio. Ambos os documentos, produzidos no âmbito de um regime de exceção por órgãos oficiais, possuem todas as características de um documento autêntico: foram produzidos por órgãos competentes dentro de suas esferas de atuação, lavrados por pessoas autorizadas e por fim devidamente preservados. Porém, foi através da contextualização desses documentos dentro do regime que os produziu que fez com que esses dois documentos, documentos esses criados para isentar o Estado de qualquer responsabilidade, que deram subsídio para o entendimento do Juiz da 7 a Vara de Justiça de São Paulo que "desqualificou a tese do Estado segundo a qual Vladimir Herzog 'teria responsabilidade exclusiva por seu suposto suicídio'"' (RODRIGUES, 2014, p. 224).

Esse caso é ilustrativo da utilização de documentos oficiais como legitimadores de discursos que, tendo em vista o contexto em que foram produzidos e, extrapolando a informação escrita no atestado de óbito e a representada pela fotografia, que por sua vez, por meio de análise da imagem, provam exatamente o oposto do que era a pretensão do produtor: foram tais documentos os responsáveis por desqualificar a tese de suicídio defendida pelo Estado. Ou seja, a prova documental serviu, ela mesma, de contraprova. Isso seria, conforme Duranti (2004) apud Rodrigues (2014), o paradoxo do poder probatório dos documentos de arquivo:

Esses documentos, [ao mesmo tempo que] trazem uma promessa de fidelidade aos fatos e ações que manifestam e para cuja realização contribuem, eles também ameaçam revelar fatos e atos que alguns interesses não gostariam de ver revelados. (DURANTI, 2004 apud RODRIGUES, 2014, p. 217).

Por fim, Rodrigues (2014) defende que "a verdade do arquivo não é absoluta, mas tributária do contexto político, que emite, por meio dos documentos de arquivo, resultante das ações de seus atores, uma 'verdade política'"' (RODRIGUES, 2014, p. 29).

\footnotetext{
${ }^{11}$ Nascido na Iugóslávia (atual Croácia) em 27 de junho de 1937 e naturalizado brasileiro, Vladmir Herzog atuava como jornalista e era filiado a base do Partido Comunista Brasileiro - PCB. Foi "convidado", em 24 de outubro de 1975, por dois agentes do Destacamento de Operações de Informações - Centro de Operações de Defesa Interna - DOI-CODI do II Exército, para prestar depoimento sobre seu envolvimento com o PCB, entidade tornada clandestina após o golpe de 1964. Devido a maus tratos durante a sua passagem pelo DOI-CODI, Herzog faleceu em 25 de outubro de 1975, um dia depois de ter sido detido Para ocultar o assassinato, os agentes do DOI defendiam que o jornalista havia morrido em virtude de ato suicida, se enforcando com uma tira de pano em sua cela (fato esse que teria como elemento de prova uma foto tirada por um perito do Instituto Médico Legal). Fonte: Instituto Wladmir Herzog. Disponível em: <http://vladimirherzog.org/biografia/>. Acesso em: 2 jul. 2015.
} 


\section{Conclusão}

Neste artigo buscamos, num primeiro momento, contextualizar as Delegacias de Ordem Política e Social - DOPS, situando seu papel - e seu aparato administrativo durante o Regime Militar (no Brasil 1964-1985). As DOPS eram órgãos civis, vinculadas às Secretarias de Segurança Pública nos estados, de característica repressiva. Pessoas e coletividades que eram encaradas pelo regime vigente como 'perigosas', de acordo com a Doutrina de Segurança Nacional ${ }^{12}$, eram fortemente vigiadas e tinham suas atividades cotidianas fartamente documentadas. Essas delegacias foram paulatinamente extintas na década de 1980, com o movimento de redemocratização. Com isso surgiu um clamor social para que essa documentação, fruto das atividades desses órgãos, fosse recolhida aos arquivos e disponibilizada ao público, servindo não apenas para pesquisas acadêmicas mas, também, como comprovação de danos causados aos cidadãos, por meio de instalação de várias comissões de indenização a pessoas detidas e/ou assassinadas pelos órgãos de repressão.

Posteriormente citamos duas tipologias documentais que eram produzidas no âmbito das DOPS, os Atestados de Antecedentes Políticos e Sociais e as Fichas Individuais. O primeiro documento dava ao cidadão que o possuía um 'status' de confiável conforme as ideias difundidas pelo regime. Já o outro, além de lhe conferir o adjetivo de 'perigoso' ou 'subversivo' causava dificuldades de toda a espécie, desde dificultar sua inserção no mercado de trabalho até demandar a convocação do indivíduo para interrogatórios tanto na DOPS, quanto em outros órgãos do aparato repressivo.

Por fim, utilizando os postulados de Rabello e Rodrigues (2014) e de Rodrigues (2014), e baseadas na análise de alguns documentos, sugerimos que é possível identificar o caráter de prova dessa documentação como 'legitimadora de discursos', já que esses documentos revelam muito mais do que escondem, contrariando totalmente a intenção dos produtores e legitimando o que o regime gostaria que ficasse oculto. Observa-se que, além da revisão da literatura e análise documental apresentada aqui, faz-se necessário outros estudos, baseados na documentação das DOPS como fonte primária, que possam fortalecer essas hipóteses ou apontar outras.

\footnotetext{
12 Segundo Palmar (2014), o conceito atribuído à Doutrina da Segurança Nacional, que foi utilizado no Brasil, advém de doutrina elaborada pelos Estados Unidos da América durante a Guerra Fria. De caráter totalitário e positivista, essa doutrina se apropria de modelos biológicos "em que cada parte contribui para o bom funcionamento do corpo [e] como consequência, qualquer segmento que não esteja nessa lógica [de funcionamento de um corpo saudável] estaria sabotando o funcionamento harmônico da totalidade e deveria ser extirpado [...]. Foi em nome dessa concepção totalitária que a Ditadura Militar [Brasileira] buscou expurgar os que considerava riscos para o seu controle militar no país" (PALMAR, 2014). Antes do período ditatorial, o Brasil já possuía Lei de Segurança Nacional, segundo trabalho de Ishaq, Franco e Sousa (2012). A primeira delas foi a Lei n. 38, de 04 de abril de 1935, que inaugurou "a prática de se criar leis especiais com punições severas para crimes contra a segurança do Estado" (ISHAQ; FRANCO; SOUSA, 2012, p. 197-198).
} 


\section{Referências}

AQUINO, M. A. et al. (Org). No coração das trevas: o DEOPS/SP visto por dentro. São Paulo: Arquivo Público do Estado; Imprensa Oficial, 2001.

AQUINO, M. A. No coração das trevas: o DEOPS/SP visto por dentro. In: AQUINO, M. A. et al. (Org.). No coração das trevas: o DEOPS/SP visto por dentro. São Paulo: Arquivo Público do Estado; Imprensa Oficial, 2001. p. 15-19.

ARAÚJO, L. et al. O Acervo DEOPS/SP. In: AQUINO, M. A. et al. (Org.). No coração das trevas: o DEOPS/SP visto por dentro. São Paulo: Arquivo Público do Estado; Imprensa Oficial, 2001. p. 23-35.

ARQUIDIOCESE DE SÃO PAULO. Brasil nunca mais. 16. ed. Petrópolis: Vozes, 1986.

BAUER, C. S. Avenida João Pessoa, 2050 - 30 andar: terrorismo de Estado e ação de polícia política do Departamento e Ordem Política e Social do Rio Grande do Sul (1964-1982). 2006. 283f. Dissertação (Mestrado em História) - Programa de Pós-Graduação em História, Universidade Federal do Rio Grande do Sul, Porto Alegre, 2006.

BELLOTTO, H. L. Arquivos permanentes: tratamento documental. $4^{a}$ ed. Rio de Janeiro: Editora FGV, 2006.

BELLOTTO, H. L. Como fazer análise diplomática e análise tipológica de documentos de arquivo. São Paulo: Arquivo do Estado; Imprensa Oficial, 2002.

BELLOTTO, H. L. Diplomática e tipologia documental em arquivos. 2. ed. Brasília: Briquet de Lemos, 2008.

BENEDITO, M. Até Marx era fichado no Dops. 2012. Disponível em: <http://www.revistaforum.com.br/blog/2012/02/ate-marx-era-fichadono-dops/>. Acesso em: 6 jul. 2015.

BRASIL. Comissão Nacional da Verdade. Relatório da Comissão Nacional da Verdade. Brasília: CNV, 2014. v. 1. Disponível em: <http://www.cnv.gov.br/images/pdf/relatorio/volume_1_digital.pdf >. Acesso em: 4 jun. 2015.

BRASIL. Presidência da República. Lei 4.341, de 13 de junho de 1964. Cria o Serviço Nacional de Informações. DOU, de 15 jun. 1964. Disponível em: <http://www.planalto.gov.br/ccivil_03/Leis/L4341.htm>. Acesso em: 9 nov. 2015.

CARNEIRO, M. L. T. O Estado Novo, o DOPS e a ideologia da segurança nacional. In: PANDOLFI, Dulce (Org.). Repensando o Estado Novo. Rio de Janeiro: FGV, 1999. p. 327-340.

COIMBRA, C. M. B. Doutrinas de segurança nacional: banalizando a violência. Psicologia em Estudo, Maringá, v. 5, n. 2, p. 1-22, 2000. Disponível em: <http://www.scielo.br/pdf/pe/v5n2/v5n2a02>. Acesso em: 7 jun. 2015. 
DREIFUSS, R. A.; DULCI, O. S. As forças armadas e a política. In: SORJ, B.; ALMEIDA, M.H.T. (Org.). Sociedade política no Brasil pós-6l. Rio de Janeiro: Centro Edelstein de Pesquisas Sociais, 2008. p. 132-181.

FAGUNDES, Pedro Ernesto. Movimento tenentista: um debate historiográfico. Revista Espaço Acadêmico, v. 9, n. 108, maio 2010. Disponível em: <file:///C:/Users/HENRIQUE/Downloads/9223-36539-1PB.pdf $>$. Acesso em: 9 nov. 2015.

ISHAQ, V.; FRANCO, P. E.; SOUSA, T. E. de. A escrita da repressão e da subversão 1964-1985. Rio de Janeiro: Arquivo Nacional, 2012.

MAGALHAES, M. D. B. A lógica da suspeição: sobre os aparelhos repressivos à época da ditadura militar no Brasil. Rev. bras. Hist., São Paulo, v. 17, n. 34, p. 1-8, 1997.

NEGRO, A. L.; FONTES, P. Trabalhadores em São Paulo: ainda um caso de polícia. O acervo do DEOPS paulista e o movimento sindical. In: AQUINO, M. A.; MATTOS, M. A. V. L. de; SWERNSSON Jr., W. C. (Org). No coração das trevas: o DEOPS/SP visto por dentro. São Paulo: Arquivo Público do Estado; Imprensa Oficial, 2001. p. 157-179.

PALMAR, A. Doutrina de segurança nacional: documentos revelados. 2014. Disponível em: $<$ www.documentosrevelados.com.br/midias/doutrina-de-segurancanacional/>. Acesso em: 16 jan. 2015.

PEREIRA, M. G.; REZNIK, L. De Polícia Federal a departamento estadual: o DOPS - evolução administrativa. In: ARQUIVO PÚBLICO DO ESTADO DO RIO DE JANEIRO. DOPS: a lógica da desconfiança. Rio de Janeiro: Secretaria de Estado de Justiça/ APERJ, 1996. p. 42-45.

RABELLO, R.; RODRIGUES, G. M. Prova documental: inscrições e materialidade. In: ENCONTRO NACIONAL DE PESQUISA EM CIÊNCIA DA INFORMAÇÃO: além das nuvens, expandindo as fronteiras da Ciência da Informação, 15., Belo Horizonte, 2014. Anais... Belo Horizonte: ANCIB; UFMG, 27-31 out. 2014. [GT1- Estudos Históricos e Epistemológicos da Ciência da Informação].

RODRIGUES, G. M. Verdade do arquivo versus Autoridade do Arquivo. In: MULLER, A.; STAMPA, I.; SANTANA, M. A. (Org.). Documentar a ditadura: arquivos da repressão e da resistência. Rio de Janeiro: Arquivo Nacional, 2014. v. 1, p. 213-232.

SOMBRA, L. H. Departamento Federal de Segurança Pública: ruptura ou permanência? In: ARQUIVO PÚBLICO DO ESTADO DO RIO DE JANEIRO. DOPS: a lógica da desconfiança. Rio de Janeiro: Secretaria de Estado de Justiça/ APERJ, 1996. p. 37-41.

XAVIER, M. Da polícia política. In: ARQUIVO PÚBLICO DO ESTADO DO RIO DE JANEIRO. DOPS: a lógica da desconfiança. Rio de Janeiro: Secretaria de Estado de Justiça/ APERJ, 1996. p. 32-36. 